\title{
A FUNÇÃO SUPERVISORA EM ENFERMAGEM De SAÚde PúBlica
}

Nilce Piva Adami*

RBEn/02

ADAMI, N.P. - A função supervisəra em Enfermagem de Saúde Pública. Rev. Bras. Enf.; DF, 28 : 20-23, 1976.

\section{INTRODUÇAOO}

Para que o produto final do setor saúde seja adequado às exigências da sociedade, as empresas que o formam vêm utilizando a supervisão como um dos mecanismos necessários à harmonização de esforços entre as diversas áreas integrantes dassas organizações.

A enfermagem, como um dos subsistemas dos órgãos de saúde, trabalha coordenadamente com os demais setores, realizando ações de supervisão a fim de manter a qualidade da assistência de enfermagem prestada à população, tendo em vista o alcance de objetivos comuns.

As escolas de enfermagem de nosso País, tradicionalmente têm incluído em seus currículos, o estudo da supervisão frente à necessidade de se preparar o profissional de enfermagem para o exerxício da função supervisora.

No entanto, apesar do avanço verificado no sistema formador de enfermagem, só recentemente encontramos a supervisão devidamente caracterizada, e, portanto, passivel de ser individualizada de outras funções administrativas.

E nosso intento neste trabalho, definir com maior precisão as atividades implícitas na função supervisora em enfermagem, tentando esclarecer o trabalho específico da enfermeira como supervisora. Para tanto, achamos oportuno apresentar como ponto de referência: o significado de alguns termos básicos e a concepção da Disciplina Enfermagem de Saúde Pública, sobre as funções cumpridas atualmente pela enfermeira. Com base nestas idéias, analisaremos posteriormente, a função supervisora na área de enfermagem em diferentes niveis de órgãos de saúde pública.

\section{DEFINIÇAO DE TERMOS BASICOS:}

\subsection{Função:}

Compreende-se por função "uma área ampla de responsabilidade, integrada por diversas atividades dirigidas para o alcance de um objetivo". (5)

* Professor Assistente Doutor - Disciplina Enfermagem de Saúde Pública da Faculdade de Saúde Pública - USP. 
ADAMI. N.P. - A Iunção supervisora em Enfermagem de Saúde Páblica. Rev. Bras. Ene; DF, 28 : 20-23, 1976.

Nestas circunstâncias, verifica-se que as atividades e respectivas tarefas derivam da função e que variam em grau de amplitude e profundidade, conforme 0 nível de atuação da enfermeira.

\subsection{Supervisão}

Supervisão em enfermagem de saúde pública é a "função administrativa que consiste em verificar se as açōes de enfermagem estão sendo executadas de acordo com bases determinadas institucionalmente. Envolve incentivo, orientação e ajuda ao pessoal, tendo em vista obter adequado, eficaz e eficiente trabalho de enfermagem para o alcance dos propósitos do serviço de saúde pública.

Em termos da sua dinâmica, a supervisão é um processo democrático de integração e coordenação de recursos humanos e materiais numa estrutura organizada". (3)

E função administrativa porque se preocupa em verificar como as açōes de enfermagem estão sendo desenvolvidas, tendo por base padrōes de trabalho determinados institucionalmente. Requer na sua dinâmica, principalmente, relacionamento pessoa a pessoa, observação do trabalho executado e orientação imediata, quando necessário; estes aspectos sem dúvida a diferenciam do controle, avaliação e das atividades de educação contínua especificas da função de ensino.

\section{FUNÇOES DA ENFERMEIRA}

Na literatura de enfermagem encontram-se trabalhos recentes, que abordam este assunto, com pequenas diferenças que representam o ponto de vista de seus autores. $(1,2,4)$.

As funçōes que apresentamos a seguir, constituem a concepção atual da Disciplina Enfermagem de Saúde Pública da Faculdade de Saúde Pública, no que se refere às áreas funcionais do trabalho da enfermeira de saúde pública.
2.1 Prestação de assistência de enfermagem

Reconhecida por todos como sendo a função primária da enfermagem, justifícando a existência das demais funçōes. Compreende um conjunto de atividades e tarefas de enfermagem dirigidas à promoção, proteção e recuperação da saúde de indivíduos, famillias e grupos da comunidade. Para que esta atenção seja a mais adequada possivel, a enfermeira utiliza uma metodologia de trabalho que requer:

- conhecimento da sítuação de saúde do indivíduo, família ou grupos da população, mediante a coleta, análise e interpretação de dados relacionados a essa situação;

- identificação das necessidades de saúde que podem ser atendidas pela enfermagem;

- elaboração do plano assistencial a ser desenvolvido, determinando objetivos, atividades, tarefas e os recursos requeridos;

- execução do plano de atenção de enfermagem, realizando as açoes mais complexas, delegando ao pessoal auxlliar as tarefas mais simples e de mediana complexidade e supervisionando o trabalho realizado por este pessoal;

- avaliação das ações prestadas em termos dos objetivos formulados.

\subsection{Ensino}

O exercício desta função requer o planejamento, organização e execução de programas de ensino visando:

- reciclagem de enfermeiras;

- formação e educação contínua do pessoal auxiliar de enfermagem;

- educação de grupos da comunidade em assuntos relacionados com a saúde;

- orientação de estagírios da área de enfermagem e de profissionais e pessoal auxdliar de outras áreas da saúde. 
ADAMI, N.P. - A funçāo supervisora em Enfermagem de Saúde Pública. Rev. Bras. En?.; DF, 28 : 20-23, 1976.

\subsection{Administrativa}

Compreende atividades de:

- planejamento, em termos de participação no planejamento do setor saúde e programação das açōes de enfermagem de saúde pública integradas no plano de saúde;

- organização da unidade* de enfermagem de saúde pública;

- direção, coordenaçāo, supervisão, controle e avaliação do trabalho realizado pelo pessoal de enfermagem.

\subsection{Assessoria}

Em assuntos de enfermagem relativos a área administrativa, de ensino e de prestação de assistência de enfermagem, requerendo atividades assistenciais dirigidas principalmente à:

- autoridades de saúde, e

- enfermeiras.

\subsection{Pesquisa}

- planejamento e execução de pesquisas em enfermagem de saúde pública;

- participação em pesquisas realizadas em saúde pública.

Estas consideraçōes apresentadas acima, configuram as áreas de trabalho da enfermeira e permitem visualizar genericamente a função supervisora.

\section{FUNÇAO SUPERVISORA}

As atividades especificas desta função são detalhadas abaixo de acordo com a extensão e complexidade implícitas no âmbito de atuação da enfermeira em diferentes níveis de serviços de saúde pública:

\subsection{A nível central}

\subsubsection{Fazer com que o significado da}

supervisão adotado institucionalmente seja conhecido e aceito pelo pessoal de enfermagem envolvido no processo de supervisão;

3.1.2 elaborar o plano geral de supervisão para a unidade de enfermagem de saúde pública do órgāo de saúde pública;

3.1.3 elaborar o plano de ação para supervisionar o trabalho realizado pelas enfermeiras de nível intermediário;

3.1.4 supervisionar o trabalho realizado pelas enfermeiras de nível intermediário;

3.1.5 assessorar em aspectos de supervisão as autoridades de saúde $e$ as enfermeiras dos escalōes hierarquicamente inferiores;

3.1.6 realizar pesquisas na área de supervisão em enfermagem.

\subsection{A nível intermediário}

3.2.1 Participar na promoção da aceitação do processo de supervisão pelo pessoal de enfermagem da região;

3.2.2 elaborar o plano de ação para supervisionar o trabalho de enfermagem desenvolvido nas unidades da regiāo, aplicando as normas elaboradas a nível central;

3.2.3 supervisionar o trabalho de enfermagem desenvolvido nas unidades da regiāo;

3.2.4 assessorar em aspectos de supervisão, as autoridades de saúde e as enfermeiras da região;

3.2.5 realizar pesquisas na área de supervisão em enfermagem.

\subsection{A nível local}

3.3.1 Participar na promoção da aceitação do processo de supervisão pelo pessoal de enfermagem da unidade sanitária; * Unidade - neste trabalho unidade é considerada em sentido amplo, podendo signifi-
car: departamento, divisão, serviço, seção ou setor. 
ADAMI, N.P. - A função supervisora em Enfermagem de Saúde Pública. Rev. Bras. Enf.; DF, 28 : 20-23, 1976.

3.3.2 elaborar o plano de ação de supervisão para a área de enfermagem da unidade sanitária;

3.3.3 supervisionar o trabalho realizado pelo pessoal de enfermagem da unidade sanitária;

3.3.4 assessorar o médico chefe da unidade sanitária em aspectos de supervisão em enfermagem.

3.3.5 realizar pesquisas na área de supervisão em enfermagem.

$\mathrm{Na}$ prática, observa-se que em diver- sos serviços de saúde pública, a enfermeira que atua a nível intermediário ou central, mesmo recebendo a denominação de supervisora, além das ações específicas de supervisão, exerce, também, outras funções administrativas e as de ensino, assessoria e pesquisa. A nível local, além destas responsabilidades restritas naturalmente ao âmbito de atuação da unidade sanitária, cabe à enfermeira, a prestação de assistência de enfermagem mais complexa à população da área programática.

\section{REFERENCIAS BIBLIOGRAFICAS}

1. HORTA, W.A. - Enfermagem: teoria, conceitos, princípios e processo. Rev. Esc. Enf. USP, 8 (1): 7-17, 1974.

2. MAILLART, V. - Enseñanza superior de enfermeria. Cronica de la OMS, 27 (6) : 263-266, 1973.

3. SÃO PAULO. Faculdade de Saúde Pública. Disciplina Enfermagem de Saúde Pública. Conclusőes sobre o estudo de supervisão em enfermagem de saúde pública. São Paulo, 1974 (mimeografado).

4. SEMINARIO SOBRE ENSENANZA DE ENF'ERMERIA A NIVEL UNIVER-
SITARIO, Lima, 1971. Informe final. Washington, D.C., Organizacion Panamericana de la Salud, 1973. (OPAS, Publicacion Científica, 259).

5. WORLD HEALTH ORGANIZATION Planing and programming for nursing services. Geneva, 1971. (Public health papers, 44).

\section{BIBLIOGRAFIA CONSULTADA}

1. ANDRADE, O.B. - Supervisão em enfermagem de saúde pública. Rev. Bras. Enfer., 27 (1): 58-70. 1974. 